\title{
Monitoring Incident Reporting To Improve Quality And Patient Safety : Sharing Malaysia Experience
}

\author{
AR Abdul Aziz PhD ; Nor Safina AM \\ KPJ Healthcare Berhad, Malaysia
}

\begin{abstract}
Hospital A monitor 17 types of incidents using incident reporting form. The form will be submitted to the Quality unit and the in charge of that unit will decide whether RCA is necessary or not based on the types of incidents by rating from level 1 (low risk) to level 4 (extreme risk).The RCA committee will investigate the incidence and come out with the conclusion and recommendations for further action by related parties. In order to ensure a good compliance among staff and doctors in this hospital, continuous briefing and teaching were conducted. Data collected will be tabulated on monthly basis and analysis will be done on yearly basis. Comparison of the trending was done between year 2014 and year 2015. For the whole year of 2014, there were 63 cases of clinical incidents reported but reduced to 48 cases in 2015. For non-clinical cases in 2014 there were 9 cases reported which increased to 11 cases in 2015.The most significant reduction of cases was related to OSH related events which reduced from 9 cases in 2014 to 2 cases in 2015. Departure from best clinical practice had recorded 10 cases in 2014 but no case was reported in 2015. Other incidents had not shown a very significant reduction in number of cases from 2014 to 2015.Policy changes were implemented from the following cases:Patient fall which had shown a reduction of cases from 16 in 2014 to 11 cases in 2015; Medication error where changes of policies were done for both pharmacy and nursing services and cases had reduced from 14 cases in 2014 to 12 cases in 2015 and Sentinel event in 2015, where the Management had raised the height of fence at the second floor. There was no change in policies for other types of incidents. Monitoring of incidents had enabled the Management of Hospital A to improve the quality of care and increase the safety provided to customers.
\end{abstract}

Keywords: Incidents reporting, Root Cause Analysis, types of incidents, trending, quality of care and safety of patients

\section{Introduction}

Incident reporting systems are a common means that hospitals use to monitor patient safety. Based on the report issued in 2010 by the Office of Inspector General, USA it was found that 13.5 percent of hospitalized Medicare beneficiaries experienced adverse events during their hospital stays that resulted in prolonged hospitalization, required life-sustaining intervention, caused permanent disability, or resulted in death. An additional 13.5 percent experienced temporary harm events that required treatment. In order to improve patient safety, incident Reporting Systems (IRS) are and will continue to be important which provide valuable insights into how and why patients can be harmed at the organizational level. However they have several limitations that should be considered. Most of these limitations stem from inherent biases of voluntary reporting systems which include: i) IRS can't be used to measure safety (error rates); ii) IRS can't be used to compare organizations; iii) IRS can't be used to measure changes over time; iv) IRS generate too many reports; v) IRS often don't generate in-depth analyses or result in strong interventions to reduce risk; vi) IRS are associated with costs (J.C.Pham, 2013).

Nurses most often identified events through patient observation and routine hospital safety assessments. Information regarding one-quarter of events was not accessible to the staff responsible for monitoring patient safety within the hospitals and for making policy changes. Hospitals investigated the events they considered most likely to yield information that would inform quality and safety improvement efforts and made few changes to policy or practices as a result of reported events. Accreditors view incident reports within the context of larger hospital quality and patient safety efforts. Officials indicated that to assess hospitals, surveyors are most likely to review the results rather than review the methods used to track hospital adverse events. Surveyors would not specifically investigate these methods, such as incident reporting systems, unless evidence of the problem emerged through the survey process. Since hospitals rely on incident reporting systems to track and analyse events, improving the usefulness of these systems is critical to hospital efforts to improve patient safety.Hospitals use incident reporting systems to monitor adverse events and other patient safety issues (D.O.Farley,2008). Incident reporting systems, which vary in design and functionality, capture and maintain reports of patient-safety-related events documented by physicians, nursing staff, or other hospital staff.

Reported patient safety events could include adverse events, "near-misses," or situations with the potential to harm patients. Completed reports typically include first-person accounts and other descriptive 
information about the events. Incident reports may also include information about the impact of the event on the patient and the causes of the events, if known.

In 1999, Institute Of Medicine (IOM) recommended that hospitals develop comprehensive patient safety improvement plans based on data collected from internal incident reporting systems and other event detection methods (P.Aspden ,2004) .IOM advised hospitals to analyse these data to identify the causes of events and to develop strategies to prevent recurrence. Incident reporting systems have limitations. First, it can be difficult to determine incidence rates based on reported data because of variability in the rate and consistency of reporting (AHRQ,2010). Second, research suggests that incident reporting systems capture only a small percentage of adverse events and that some categories of events are underrepresented (T.K.Nuckols, 2007).Additionally, the rate and consistency of event reporting by hospital staff often varies.

Despite these limitations, stakeholders note that incident reporting systems have advantages. These include systems' familiarity among hospital staff and the advantages derived from involving frontline personnel in identifying safety hazards for the organization. Compared to other event detection methods commonly used in hospitals, incident reporting systems are thought to capture a wider range of events at a lower cost to hospitals(K.G.Shojania, 2010)

In a November 2010 report, OIG estimated the national incidence rate of adverse and temporary events in hospitals.31We found that 27 percent of hospitalized Medicare beneficiaries experienced at least one adverse event (13.5 percent) or temporary harm event (13.5 percent) during hospitalizations that ended in October 2008. These rates were projected to all beneficiaries hospitalized during October 2008 (OIG, 2008).

Incident reporting system can be used for the following purposes:

\section{To identify local system hazards}

Information provided in IRS can identify hazards, understand the complex inner workings of our healthcare system and design interventions to reduce risks to future patients. For example, several years ago, a nurse at Johns Hopkins Hospital reported that her patient was sent the incorrect medication from pharmacy. Although the label was correct, she noticed that the pill looked different than the metoprolol that she normally gave. As it turns out, the pharmacy label-maker had received a software update and had defaulted back to incorrect settings. Such a report, of a near-miss, likely prevented hundreds of medication errors. Currently, the most valuable lessons from these IRS occur from single cases. A variety of tools that provide a systematic analytic framework can help clinicians learn from these events (Pham.JC et al, 2010)

\section{To aggregate experiences for uncommon conditions}

The aggregation of uncommon cases can provide insight into failure modes and risks. In the wrong-site surgery for example aggregation of 132 wrong-site surgical events in the state of Colorado revealed that $100 \%$ of the cases involved a communication failure and $72 \%$ did not have a time-out performed (Stahel.PF, 2010)

This required 6 years and data from 5937 physicians. A single institution would not have enough experience/events to identify such patterns and potential vulnerabilities. Therefore, the aggregation and analysis of uncommon cases from the IRS across many organizations can be useful in this way.

\section{Can be used to share lessons within and across organizations}

The lessons learned from IRS can be used to educate, inform, and prevent other organizations from experiencing the same adverse events. Such a system for sharing can occur at a local, regional, national, or international level. For example, the Canadian Global Patient Safety Alerts (GPSA) system is a repository of case details and lessons learned from adverse events. Healthcare organizations can search the system to identify adverse events, their known failure mechanisms, and interventions that may be implemented to prevent their occurrence. This allows healthcare organizations to share the most valuable aspect of IRS (lessons learned) without the burdens of incident investigation and confidentiality concerns. Given that the same adverse events are occurring around the world, such sharing is sorely needed.

\section{Can be used to increase patient safety culture}

The real implementation and use of a reporting system (the full reporting cycle with: reporting, analysis, and implementation of system changes in analogy to the Plan-Do-study-Act cycle of quality management) within a healthcare institution communicates a lot about how the organization views patient safety. The implementation and communication of such a system to staff members can be a method of changing patient safety culture. This effect is apart from the advantages of the IRS itself.

For KPJ Penang Specialist Hospital, incident reporting system started in 2014 by monitoring the following types of incidences: i. Patient fall, ii. Medication related events, iii. Sentinel events, iv. Blood transfusion events, v. sharp injury, vi. OSH related events, vii. Discharge related incidents, vii. Discharge related incidence, viii. Nursing services related incidents, ix. O\&G services, x. ICU services, xi. OT services \& CSSD, 
xii.Departure from clinical best practices, xiii.Hospital wide general events, xiv. Equipment/device related incidents, xv. Customer feedback, xvi. Medical records related incidents, xvii. Laboratory services related incidents, xviii. DID related incidents, xix. Radiotherapy related incidents, xx. Food services related incidents, xxi. Discharge related incidents(non-clinical), xxii. Financial related incidents, xxiii. Security related incidents, xxiv. Human capital management, xxv.Housekeeping, xxvi.Other events.Reporting can be made by any staff or doctors using Incident Reporting Form and later to be handed over to Deputy Manager of Quality Services. The Deputy Manager will classified the incident according to the guideline produced by KPJ Healthcare Berhad (CRM/RCA/27Feb07). After analysing the incident the Deputy Manager will classified into the following categories for Root Cause Analysis (RCA) :

Level 1 (Low risk)

-no investigation required

Level 2(Moderate risk)

Level 3(High risk)

-basic investigation, monitor trend

and full RCA

Level 4(extreme risk)

-intermediate investigation and RCA, consider full investigation

If RCA is necessary the RCA committee will investigate the incidence and come out with the conclusion and recommendations for further action by related parties.In order to ensure a good compliance among staff and doctors in this hospital, continuous briefing and teaching were conducted. Data collected will be tabulated on monthly basis and analysis will be done on yearly basis. For the purpose of this report trending for 2014 and 2015 will be analysed.

\section{Objectives}

i. To tabulate all data that had been collected for year 2014 and 2015

ii. To analyse all data for 2014 and 2015

iii. To develop trending by comparing data collected in 2014 with 2015

iv. To find out what interventions that had been implemented to reduce the incidents based on types of incident

\section{Methodology}

Retrospective study was conducted for a period of two years from 2014 to 2015 . All data collected will be tabulated based on various types of incident. A trending will be done to compare the data collected in 2014 again data collected in 2015. Analysis will be done to see the outcome of incidents' monitoring. For cases where process improvements had been introduced, data will be analysed to see whether the implementation of the improvement process managed to reduce the incidents.

\section{Results}

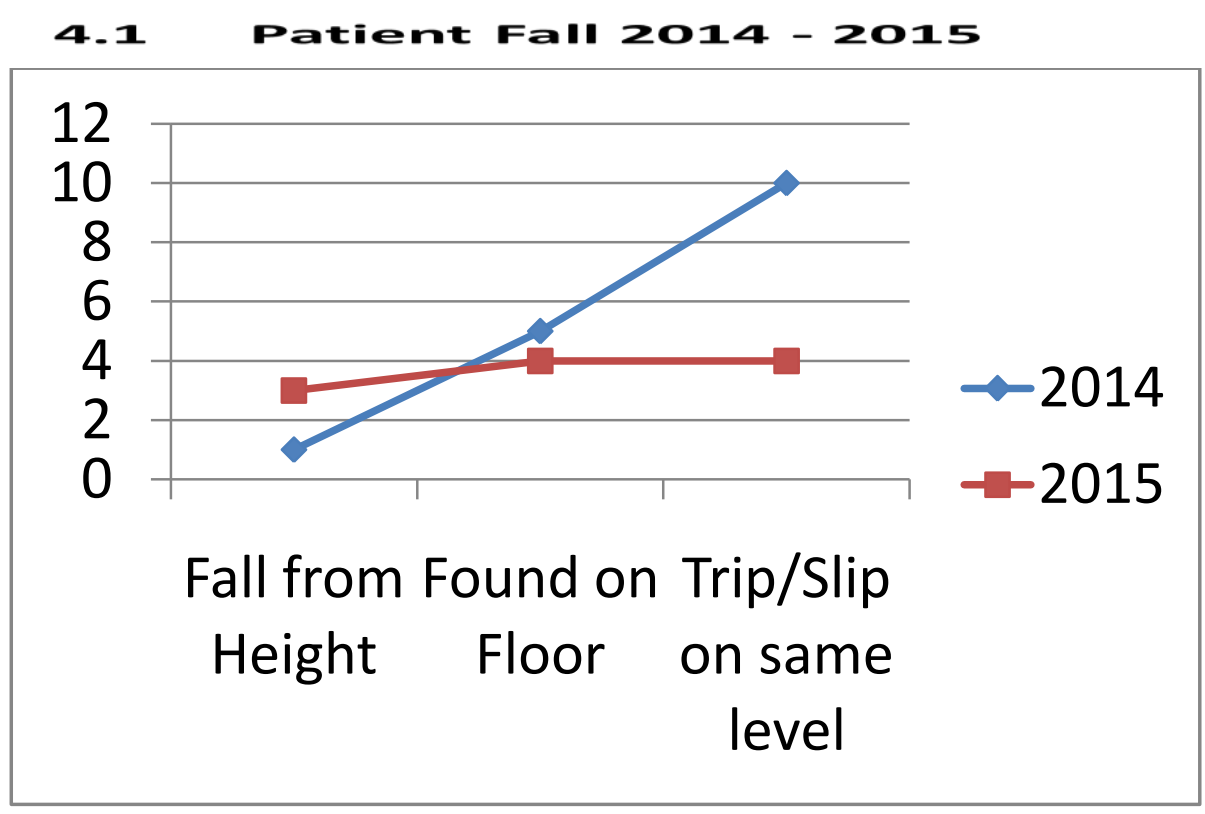




\begin{tabular}{|l|c|c|}
\hline \multicolumn{1}{|c|}{ YEAR } & $\mathbf{2 0 1 4}$ & $\mathbf{2 0 1 5}$ \\
\hline Fall from Height & 1 & 3 \\
\hline Found on Floor & 5 & 4 \\
\hline Trip/Slip on same level & 10 & 4 \\
\hline
\end{tabular}

\subsubsection{Patient Fall in 2015}

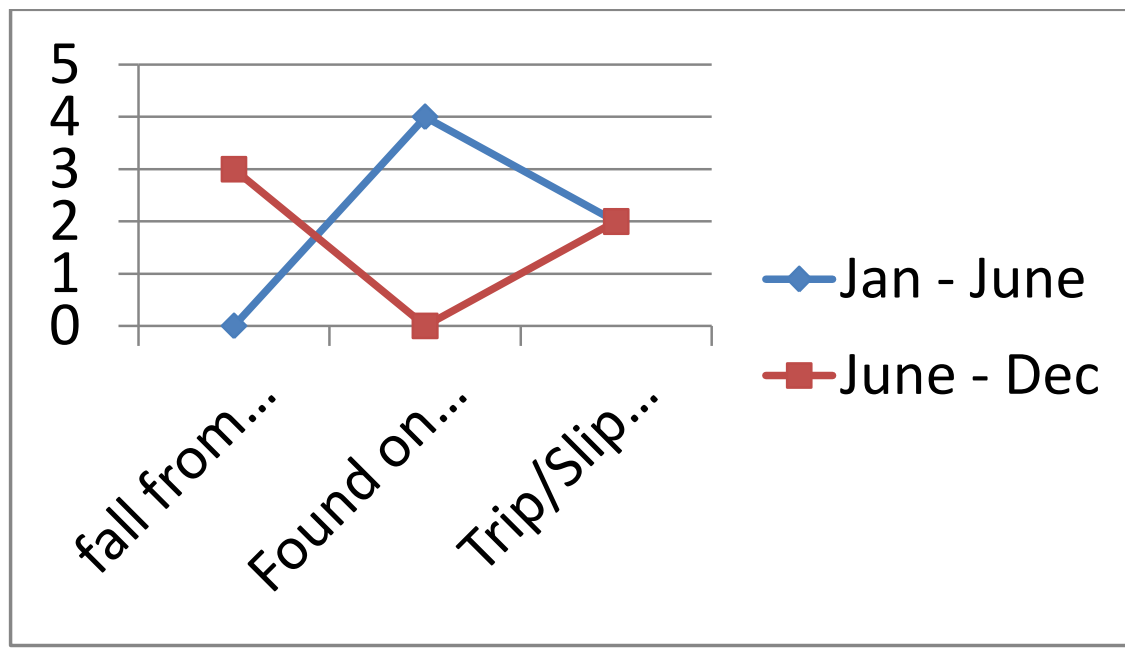

\begin{tabular}{l|c|c|}
\hline \multicolumn{1}{|c|}{ YEAR } & Jan - June & June - Dec \\
\hline fall from Height & 0 & 3 \\
\hline Found on Floor & 4 & 0 \\
\hline Trip/Slip on Same & & \\
\hline Level & 2 & 2 \\
\hline
\end{tabular}

\subsection{Medication related events 2014 and 2015}

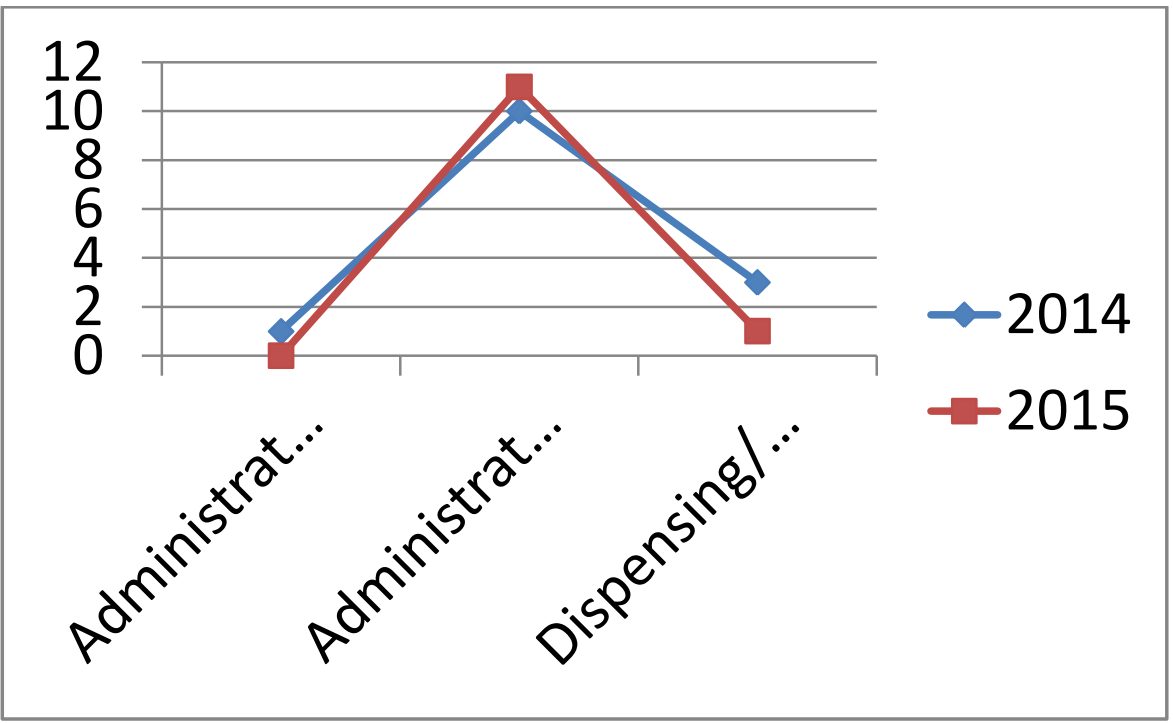




\begin{tabular}{|l|c|c|}
\hline \multicolumn{1}{|c|}{ YEAR } & 2014 & 2015 \\
\hline Administration (Nursing) Near miss & 1 & 0 \\
\hline Administration (Nursing) Adverse Event & & 11 \\
\hline Dispensing/Preparation (Pharmacy) & 10 & 1 \\
\hline
\end{tabular}

\subsubsection{Nursing Medication Related Event 2015}

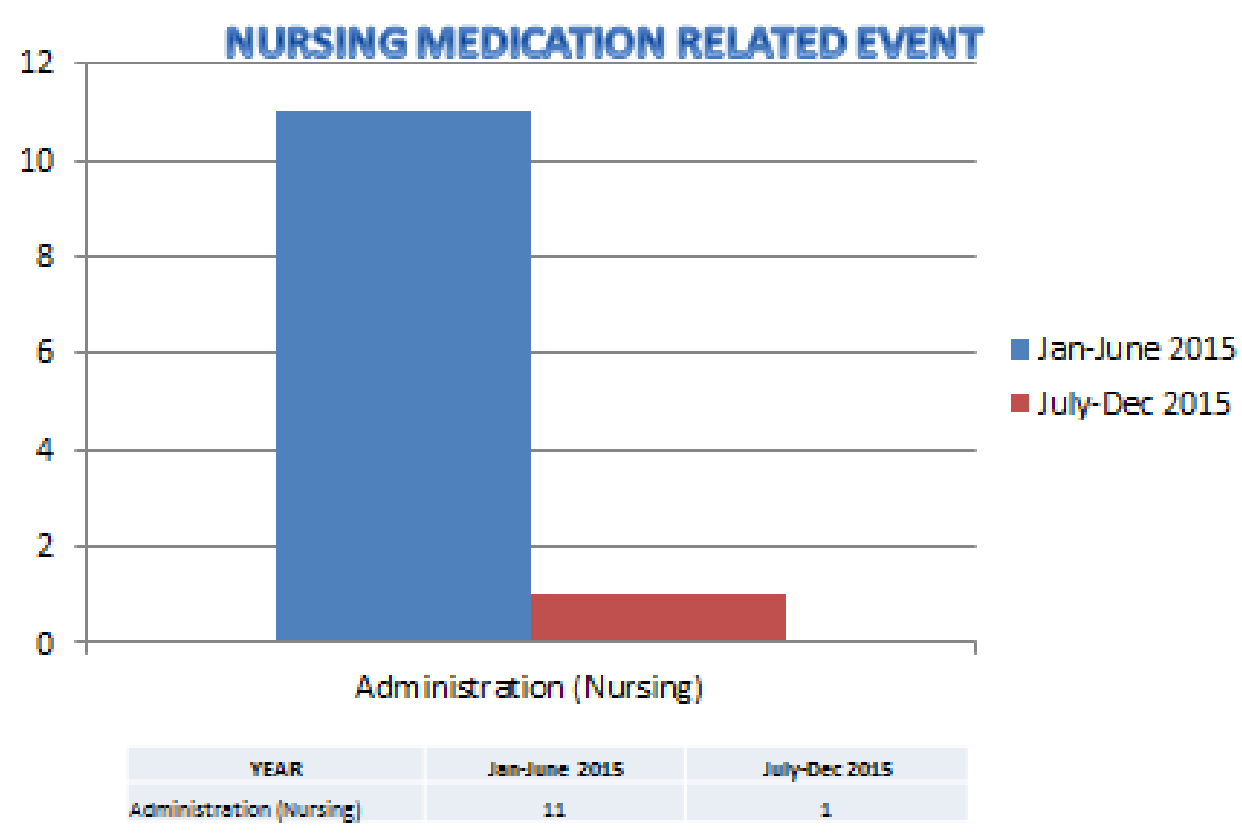




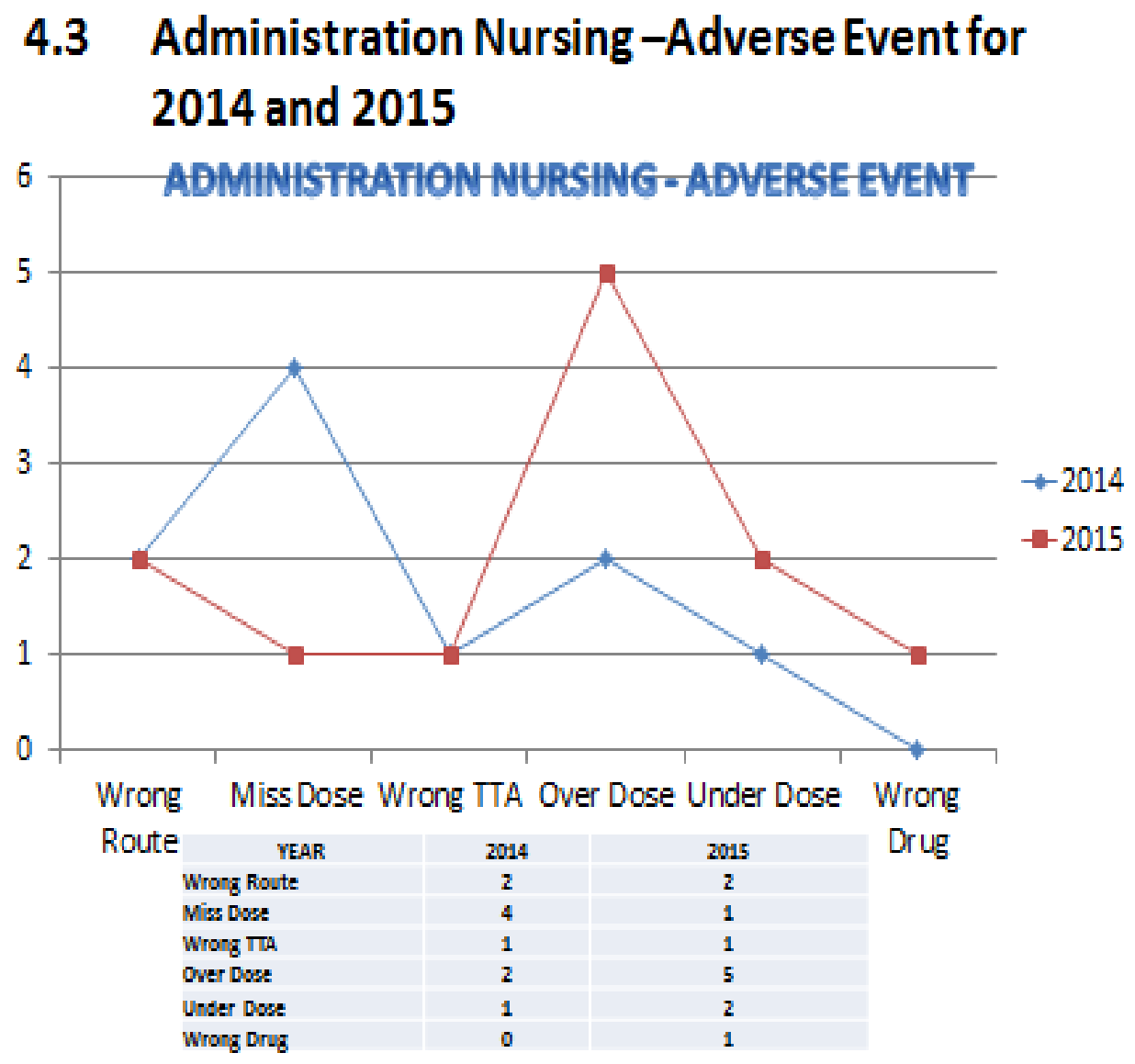

4.4 Dispensing / Preparation (Pharmacy) for 2014 and 2015

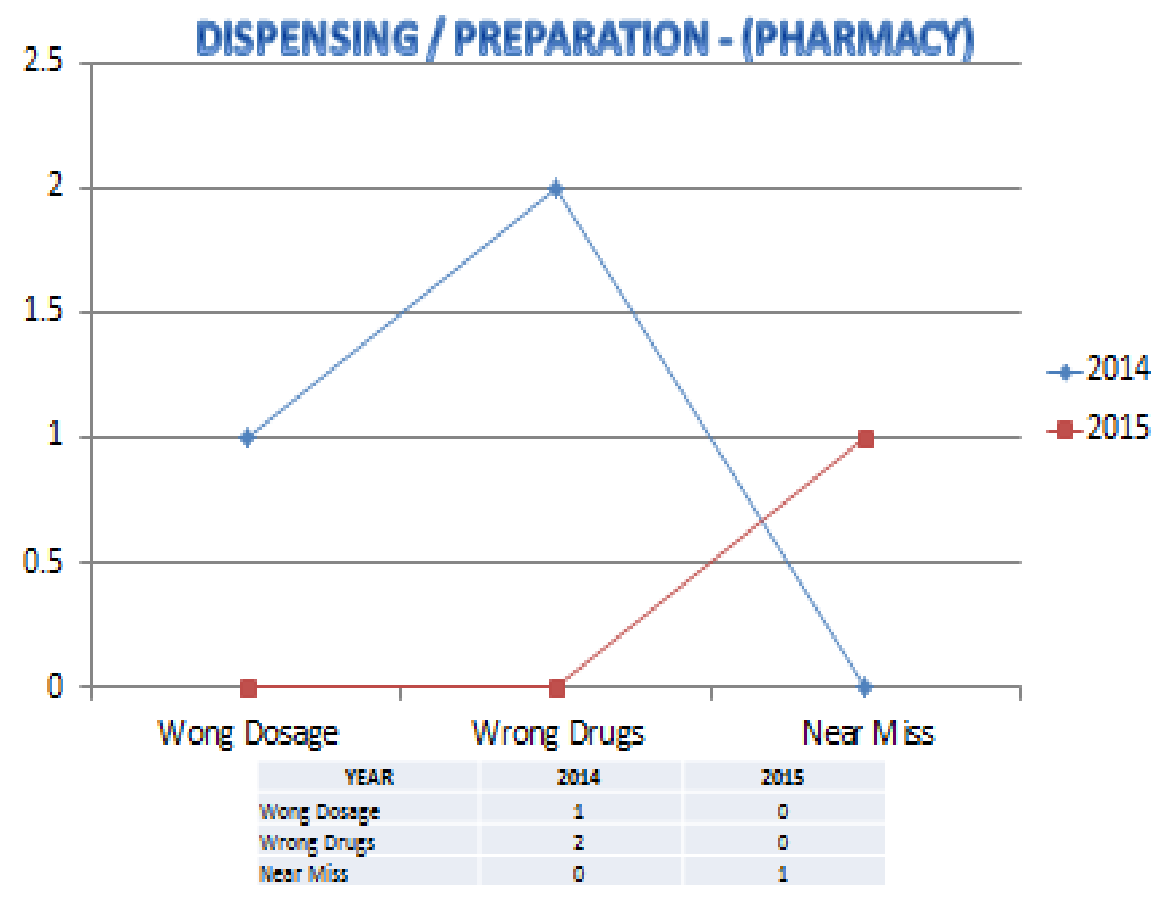




\subsection{Sentinel Events for 2014 and 2015}

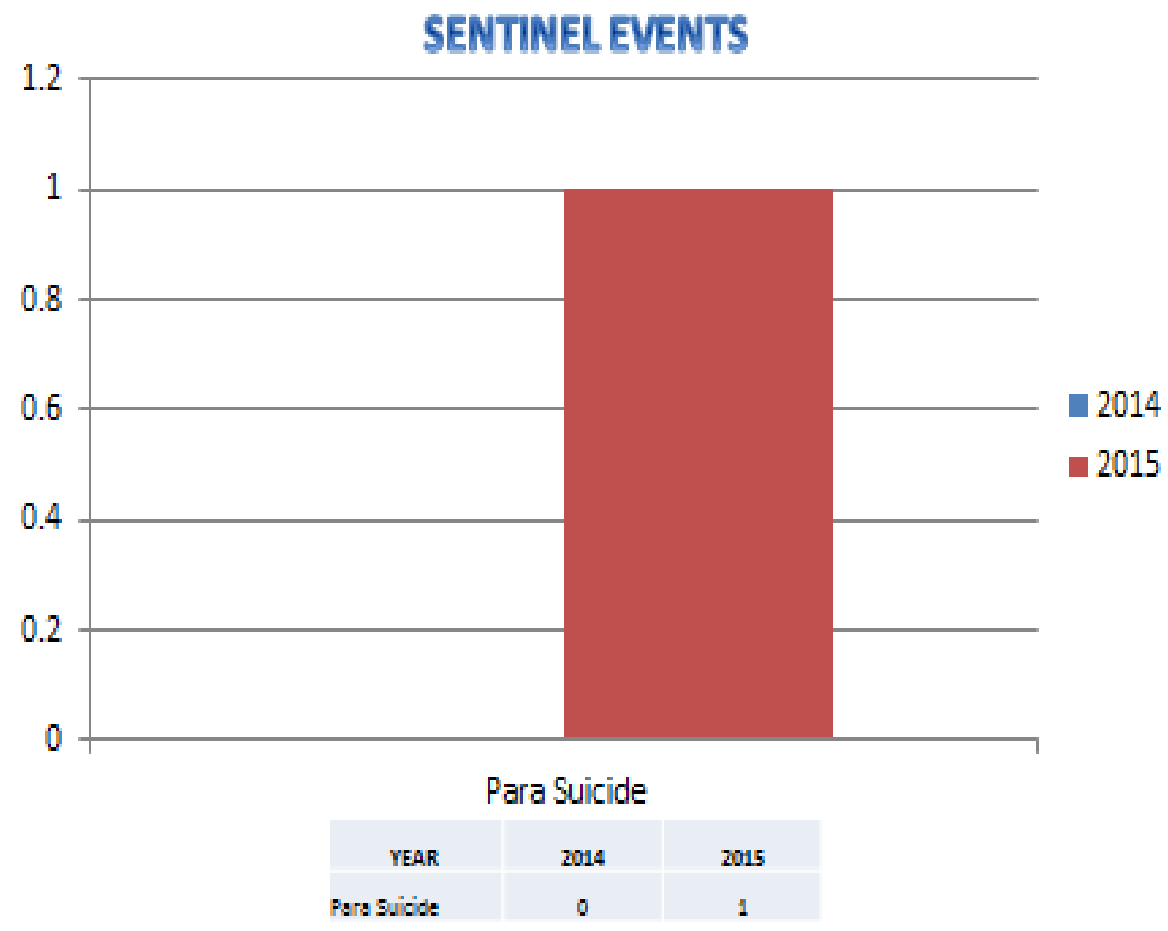




\subsection{Blood Transfusion- related events for 2014 and 2015}

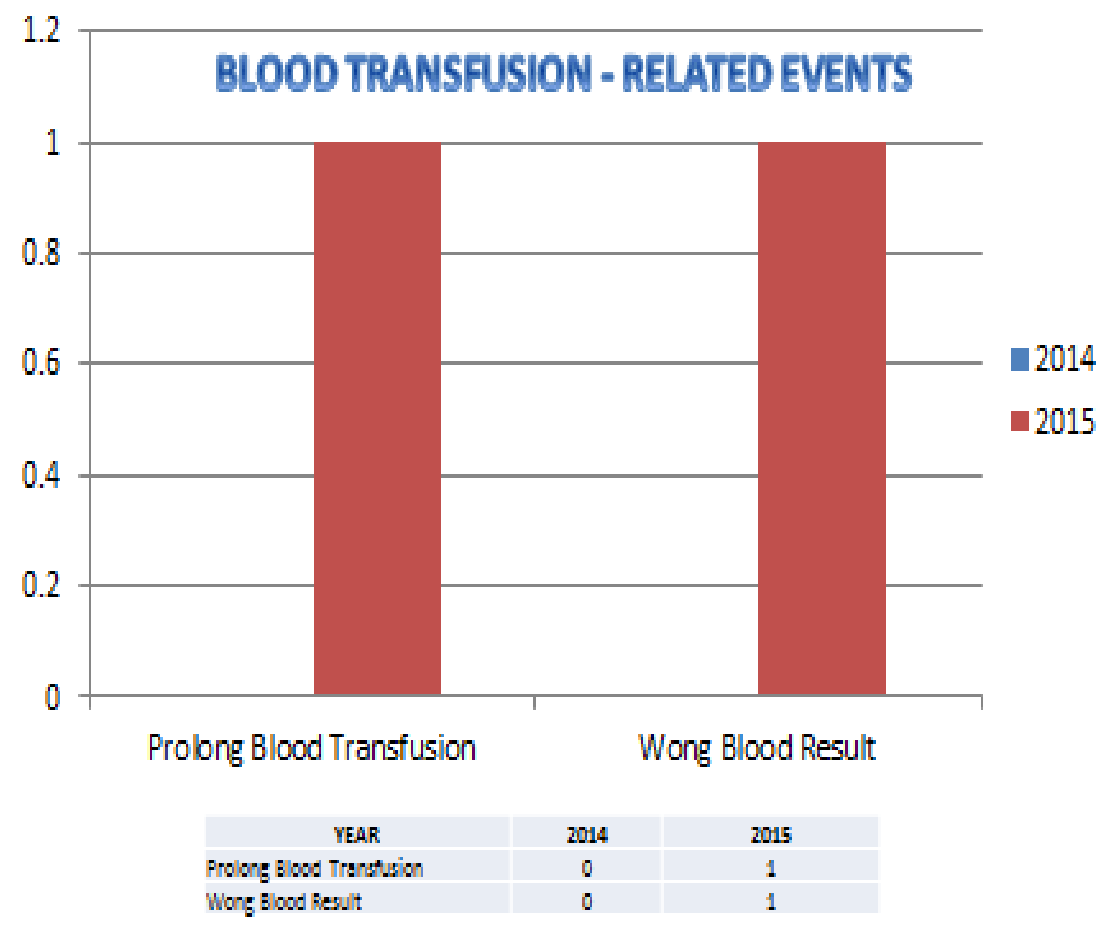

\subsection{Sharp Injury for 2014 and 2015}

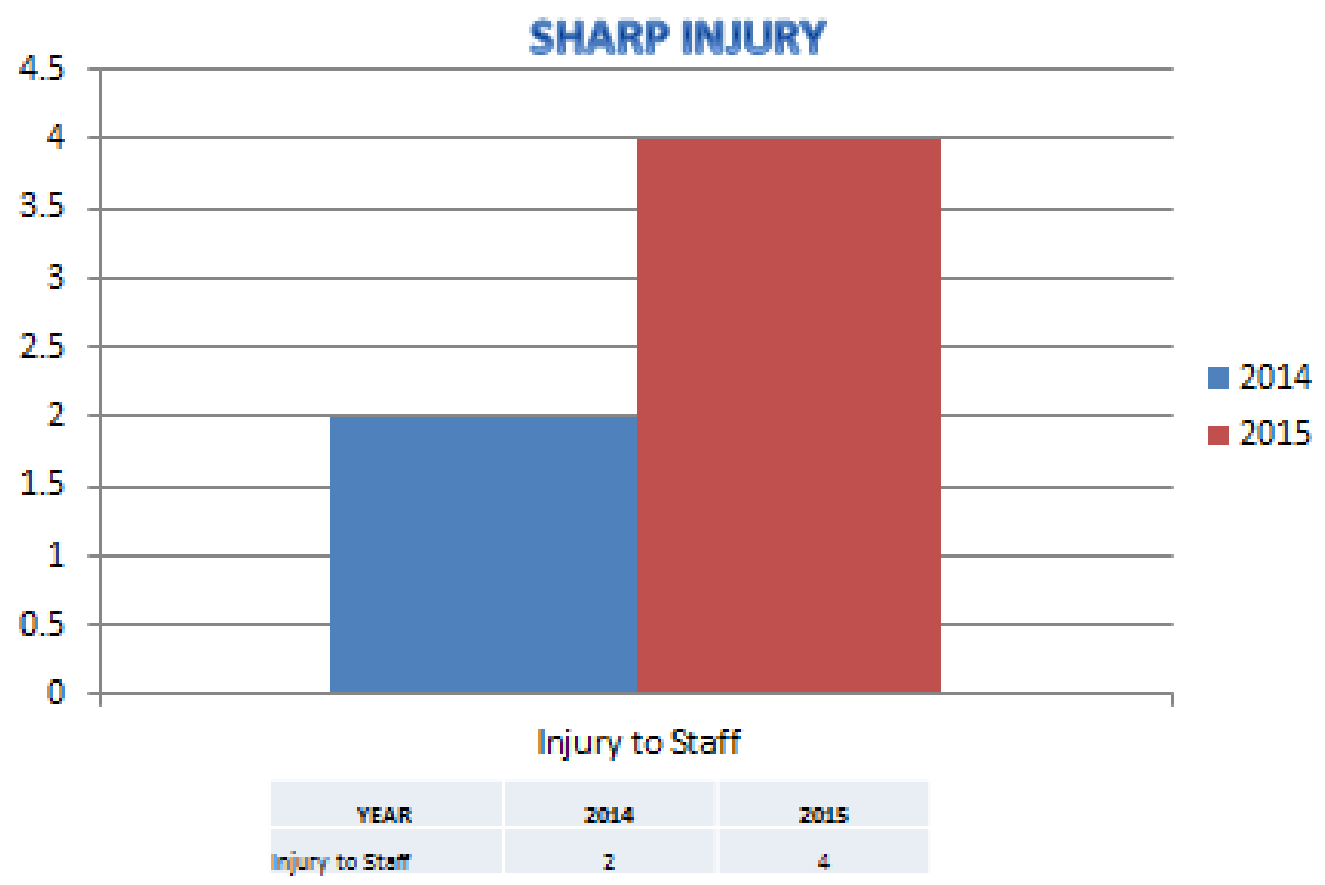




\subsection{OSH related events for 2014 and 2015}
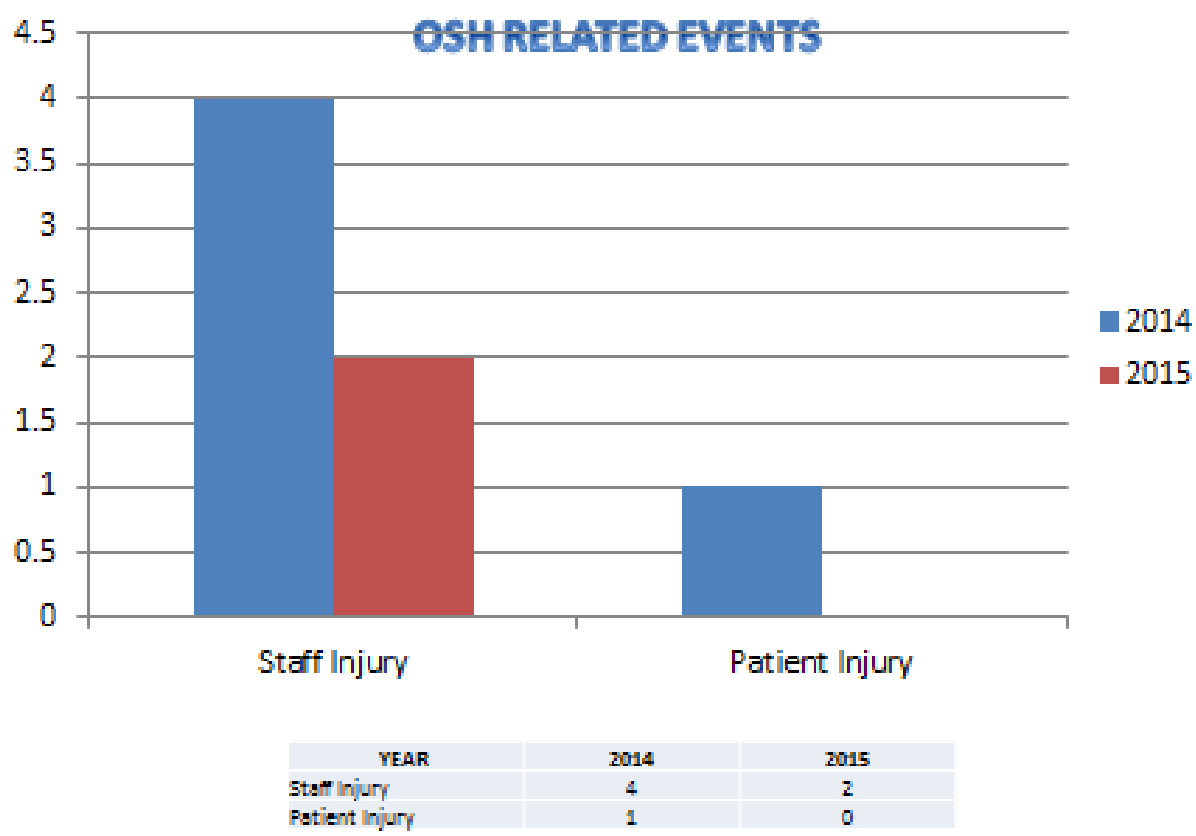

\subsection{Nursing Services-nursing related incidents for 2014 and 2015}

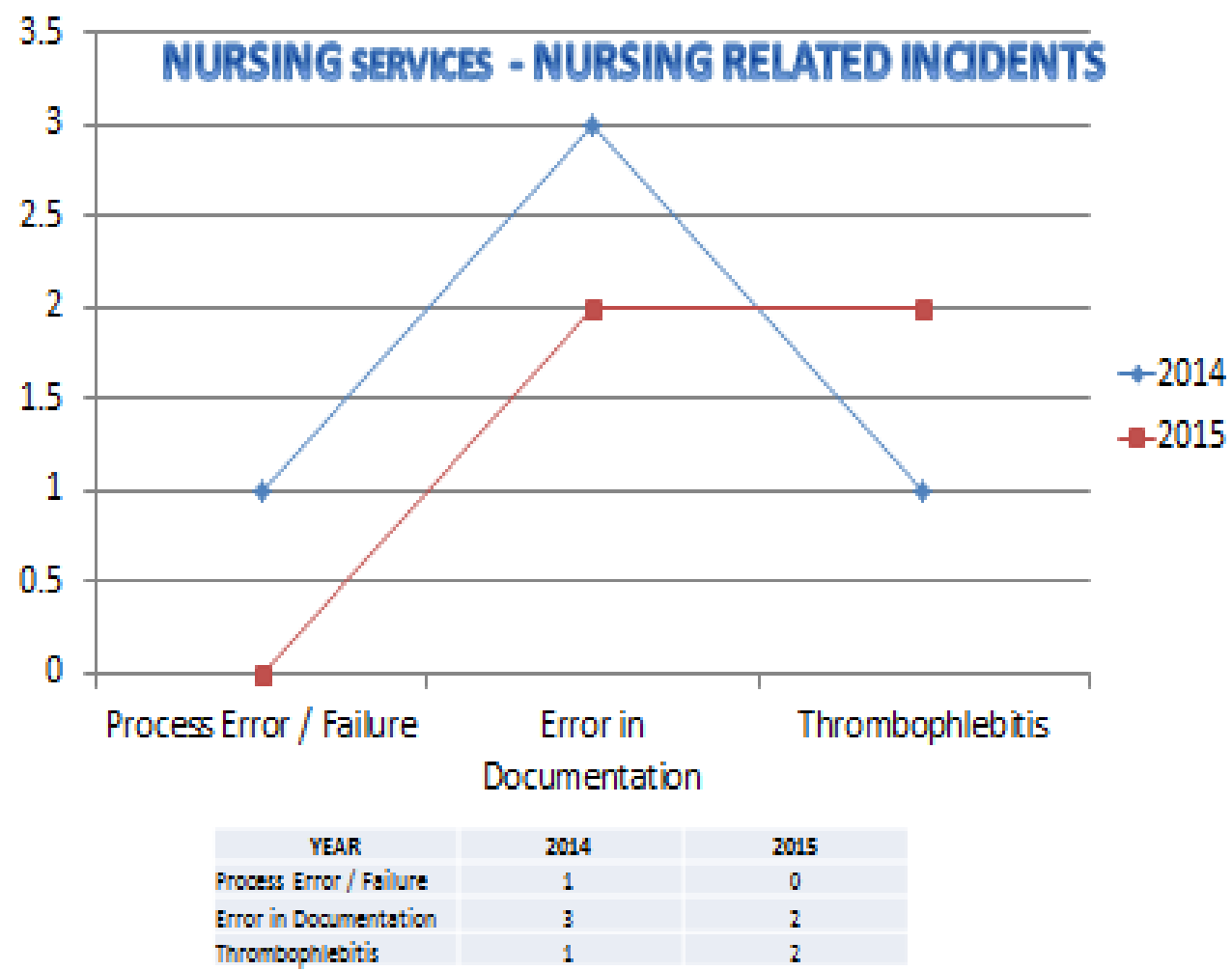



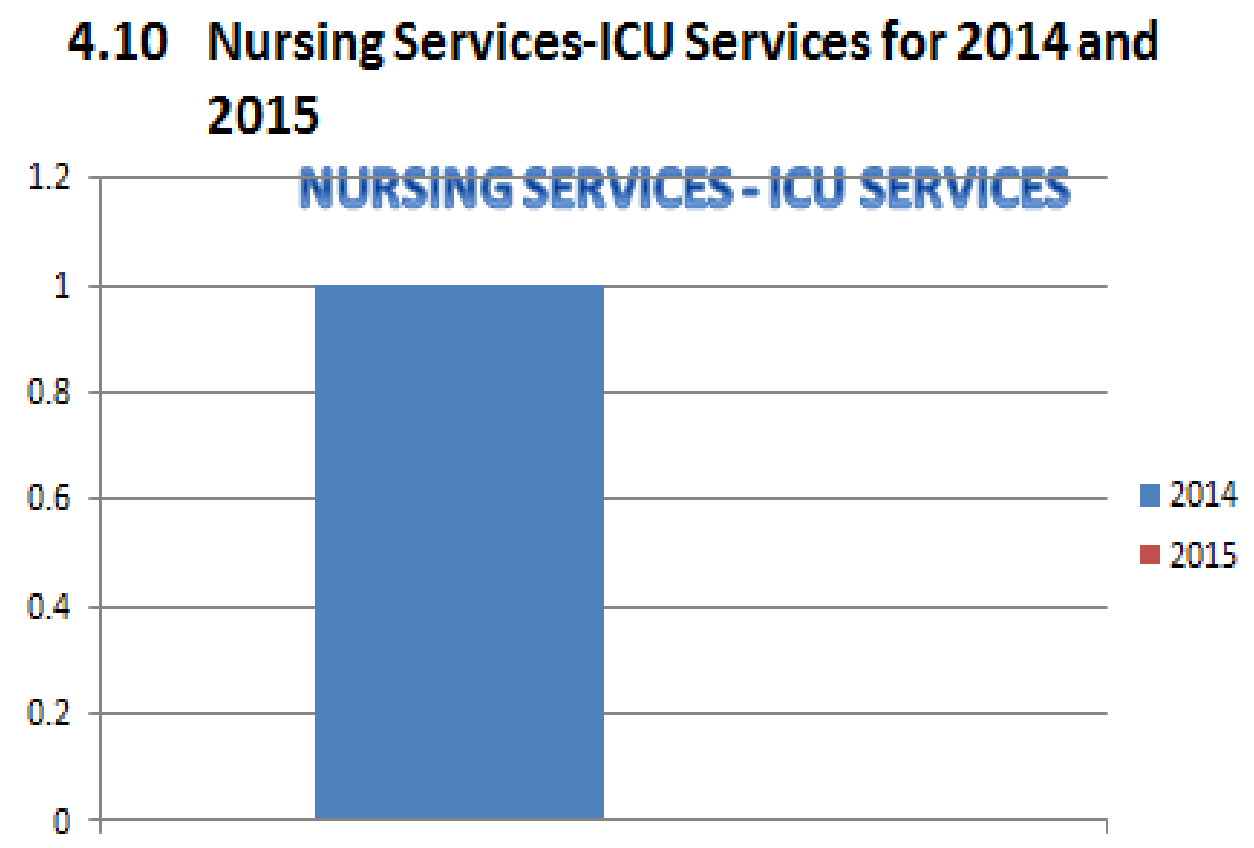

ETT/Monitoring Lines Dislodged

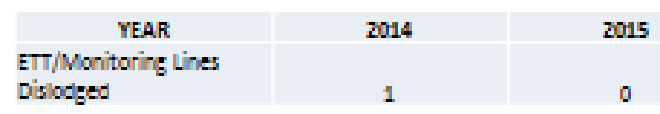

4.11 Nursing Services-OT \& CSSS Services for 2014 and 2015

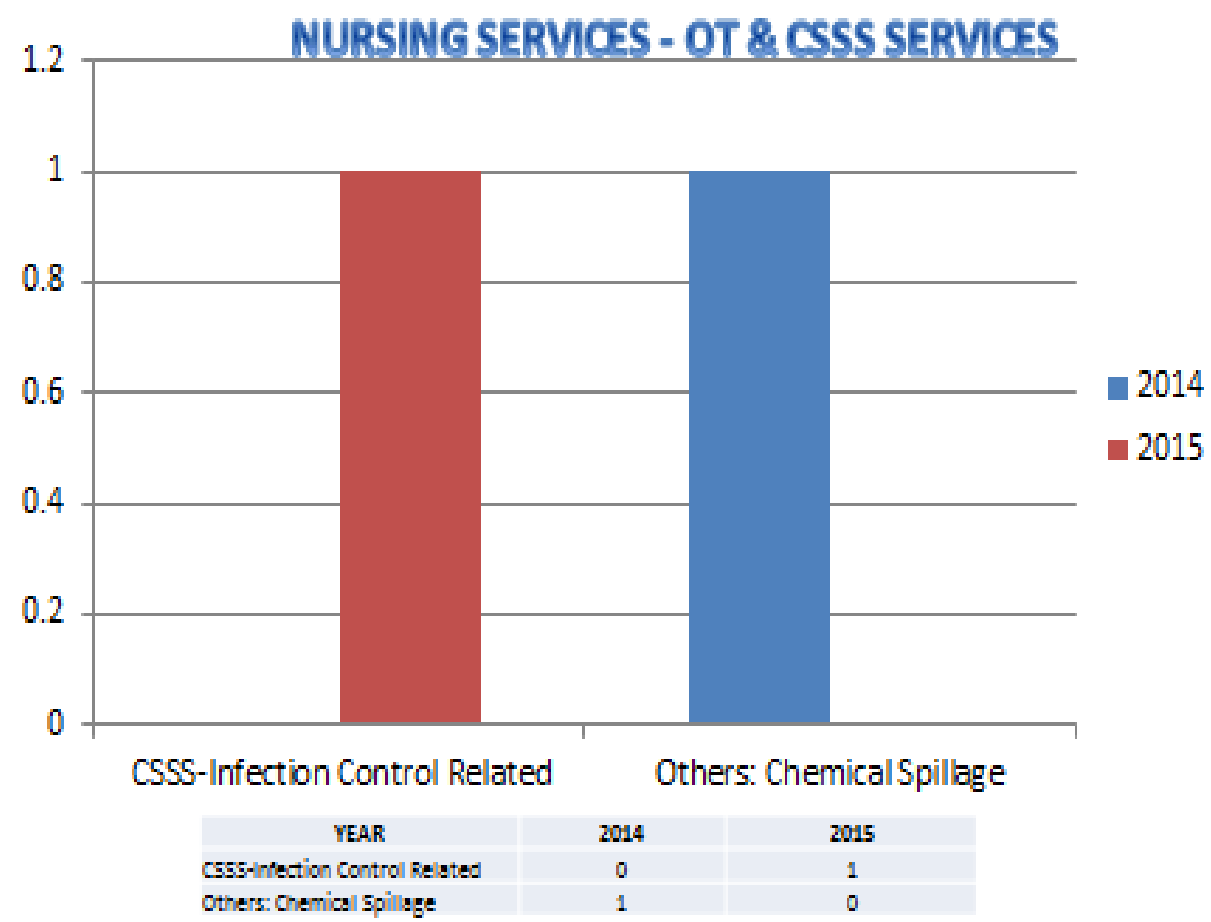


4.12 Nursing Services-Departure from Best Clinical Practice for 2014 and 2015

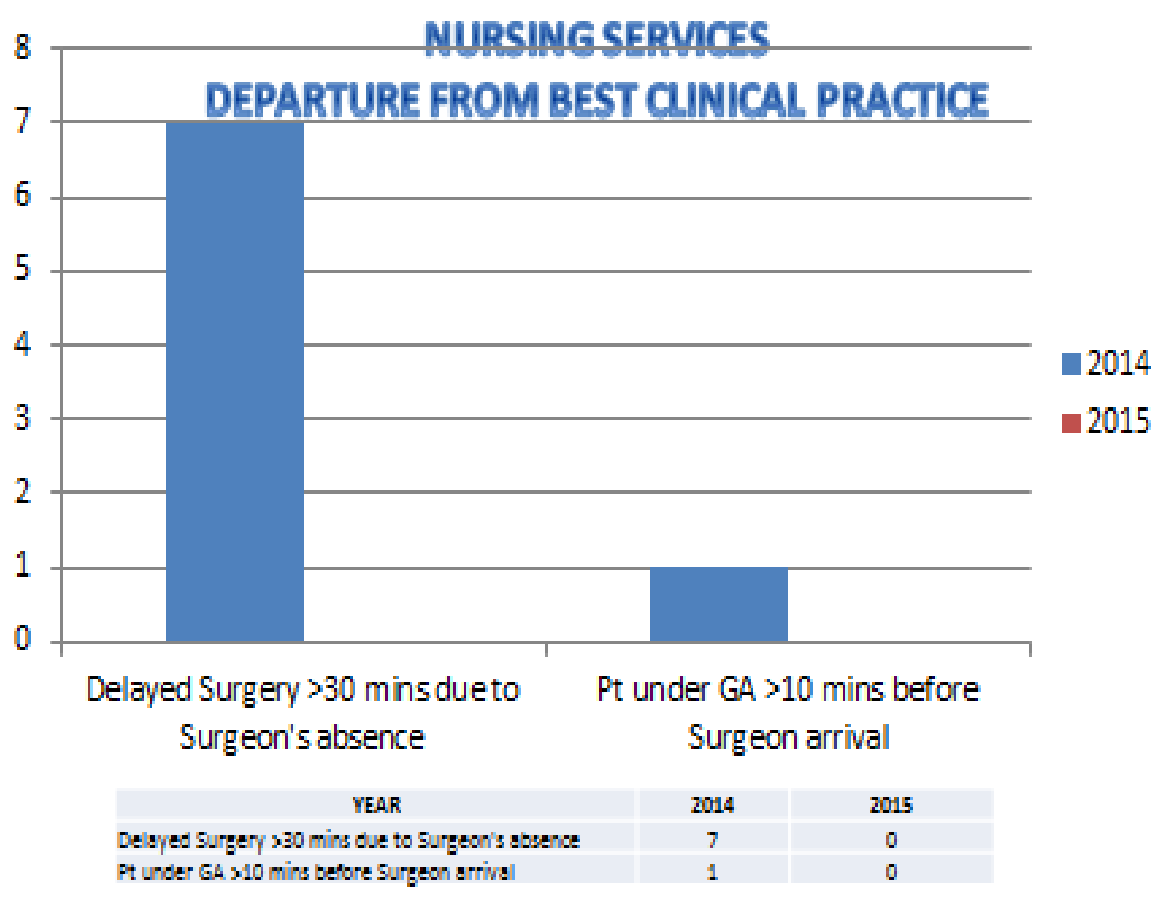

4.13 Hospital Wide-General Event for 2014 and 2015

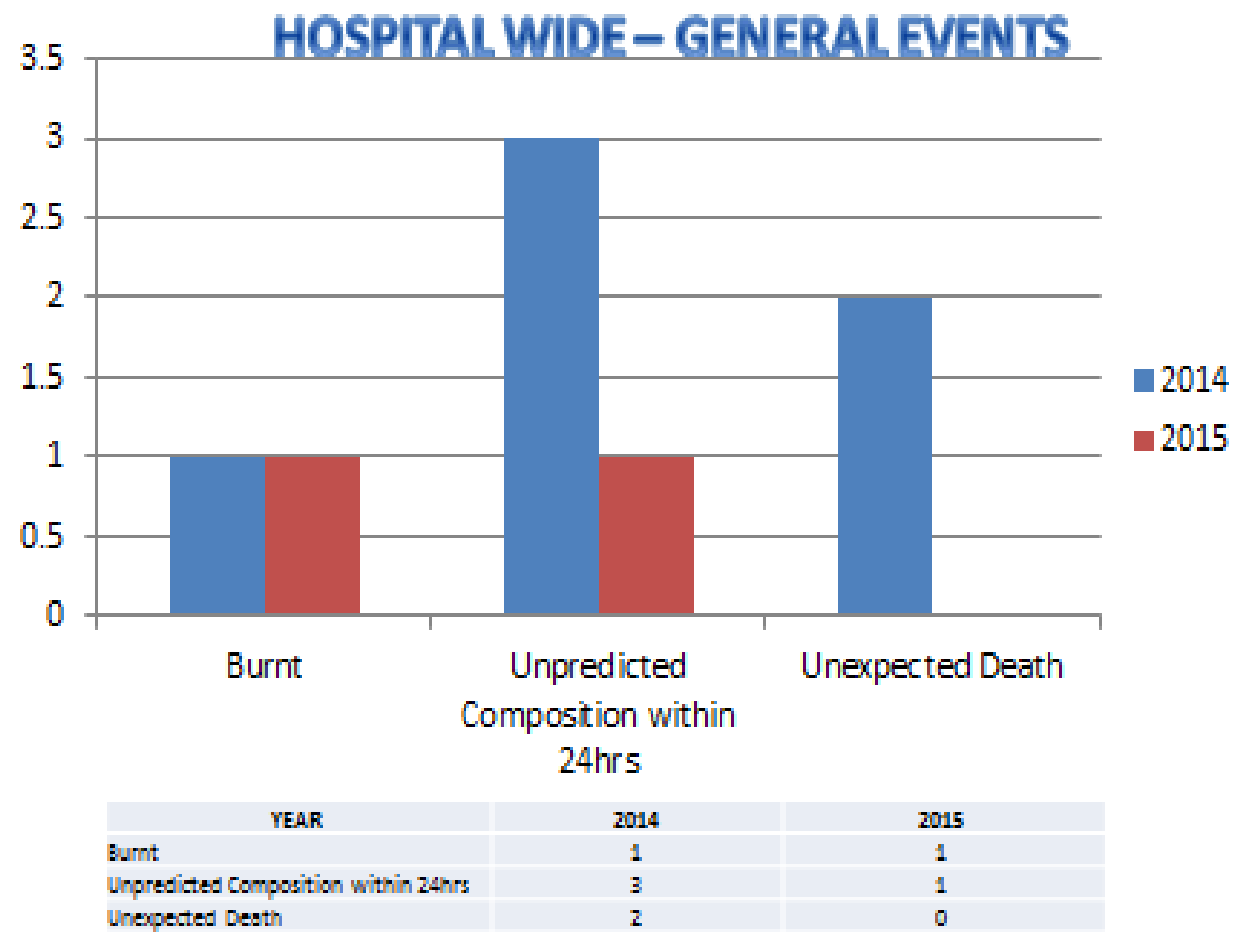




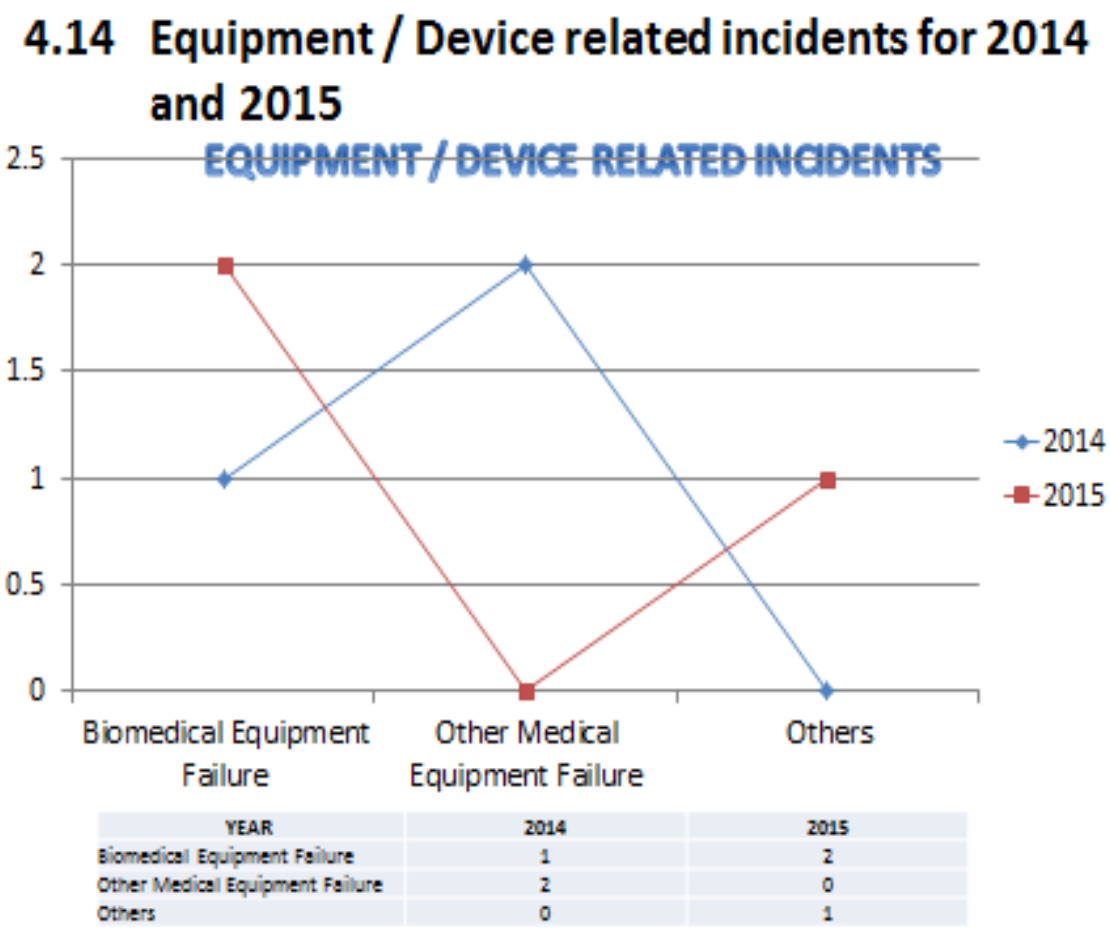

\subsection{Medical Record related incidents for 2014 and 2015}

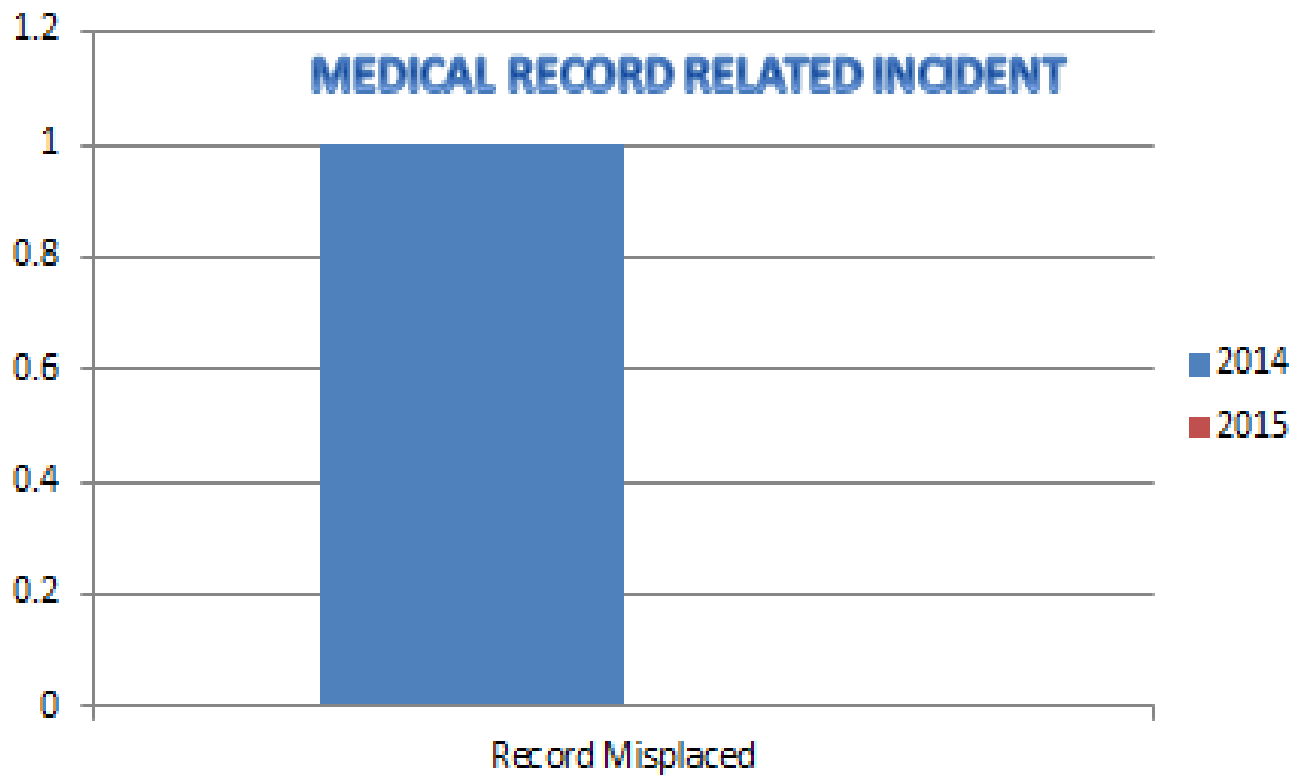

\begin{tabular}{|c|c|c|}
\hline YEAR & 2014 & 2015 \\
\hline Record Mirplaced & 1 & 0 \\
\hline
\end{tabular}




\subsection{Clinical Support Incidents: Diagnostic Imaging} Service related incident for 2014 and 2015

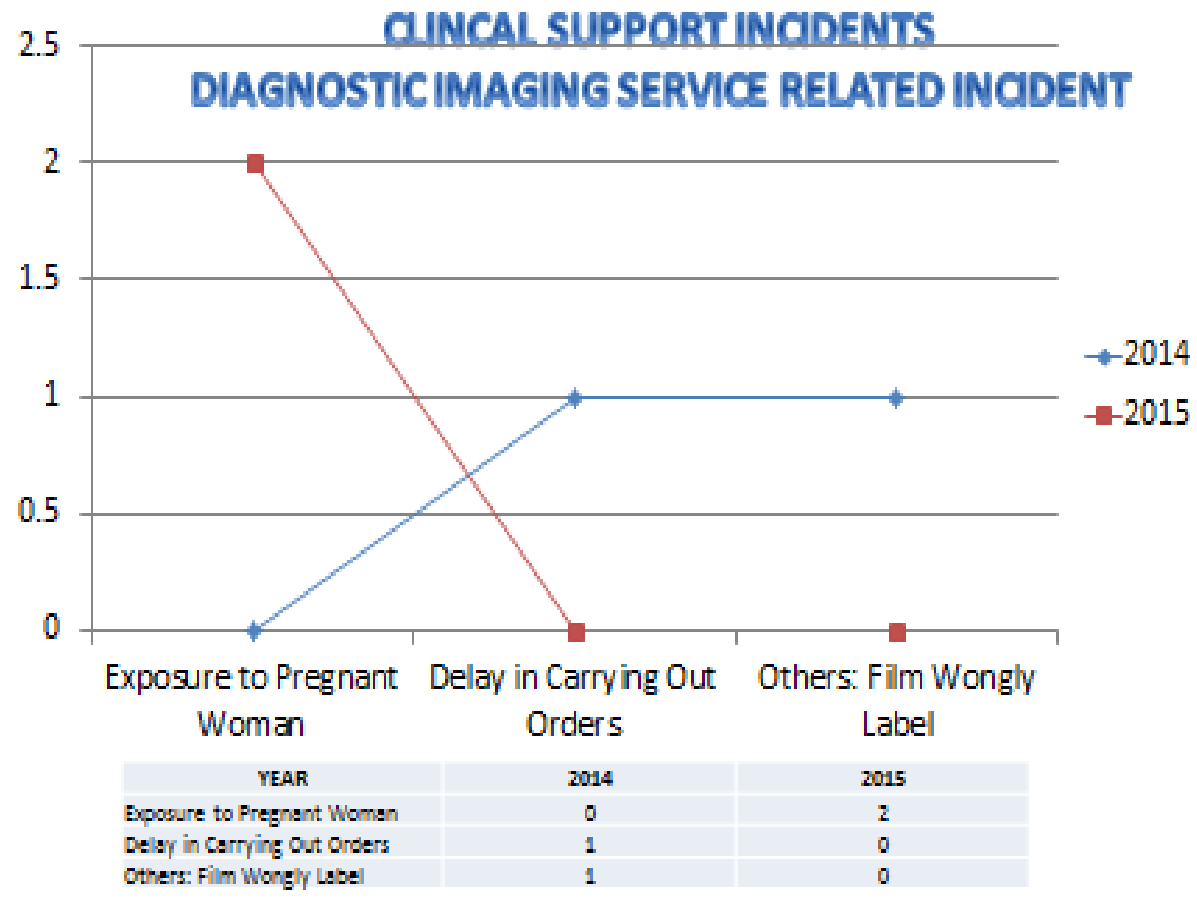

\subsection{Clinical Support Incidents: Laboratory Service incident for 2014 and 2015}

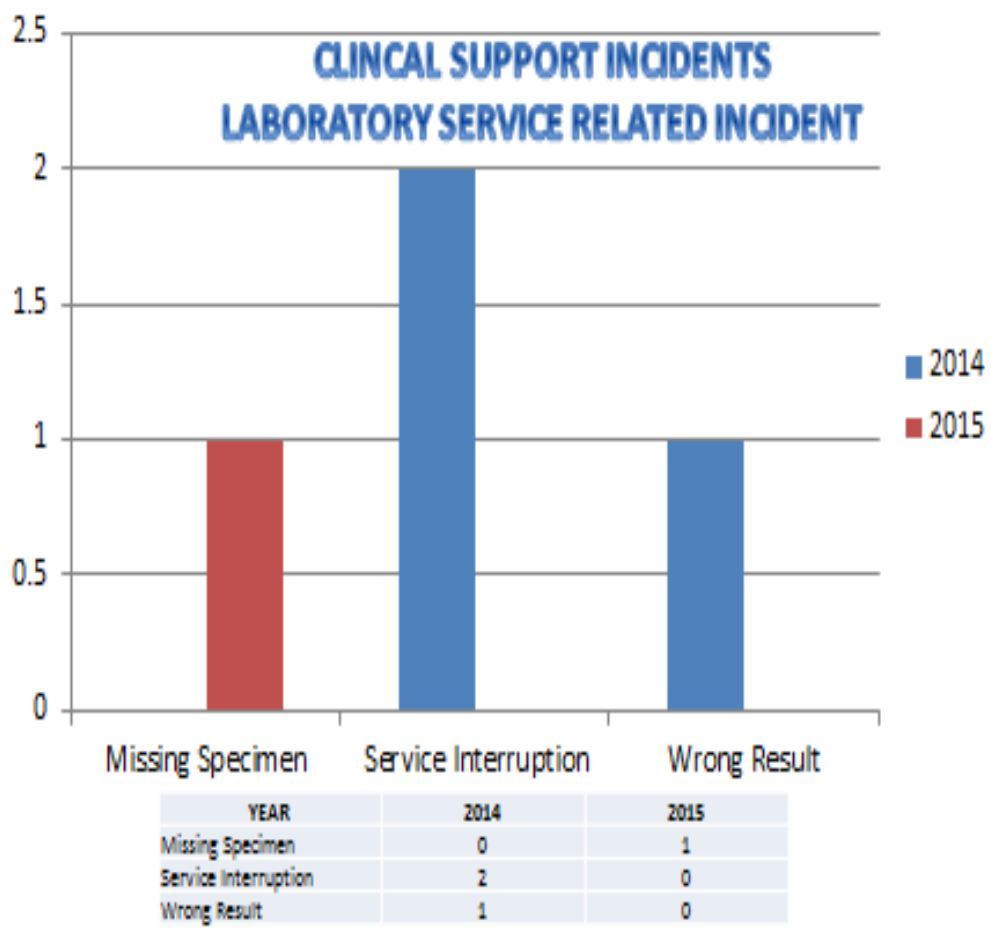




\subsection{Clinical Support Incidents: Diagnostic Imaging Service related incident for 2014 and 2015}
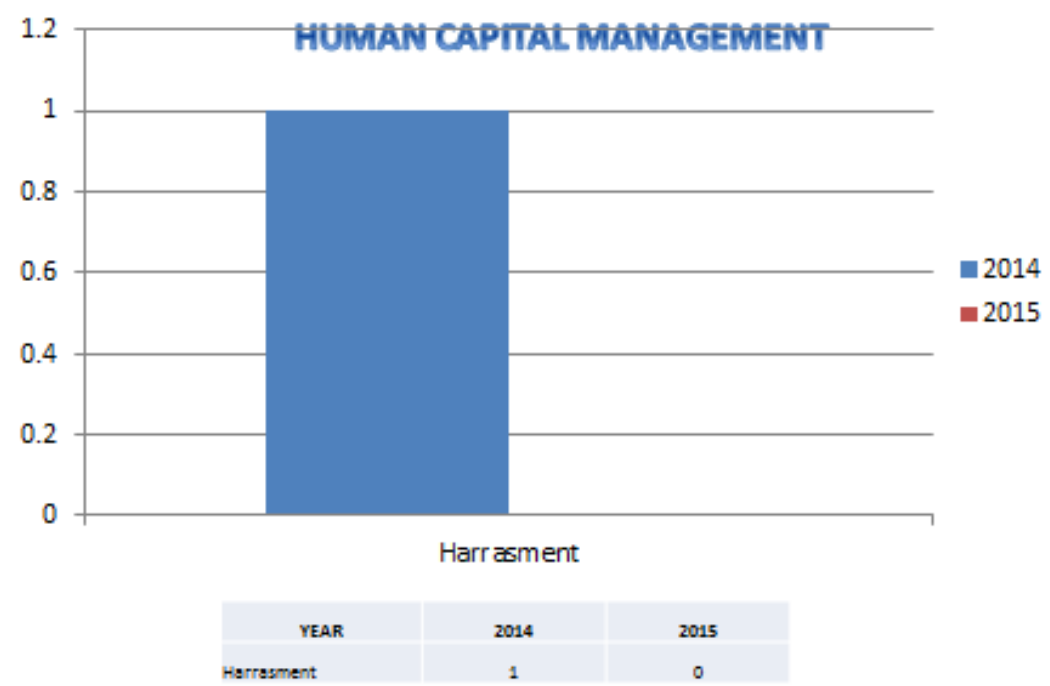

\subsection{Other Events for 2014 and 2015}

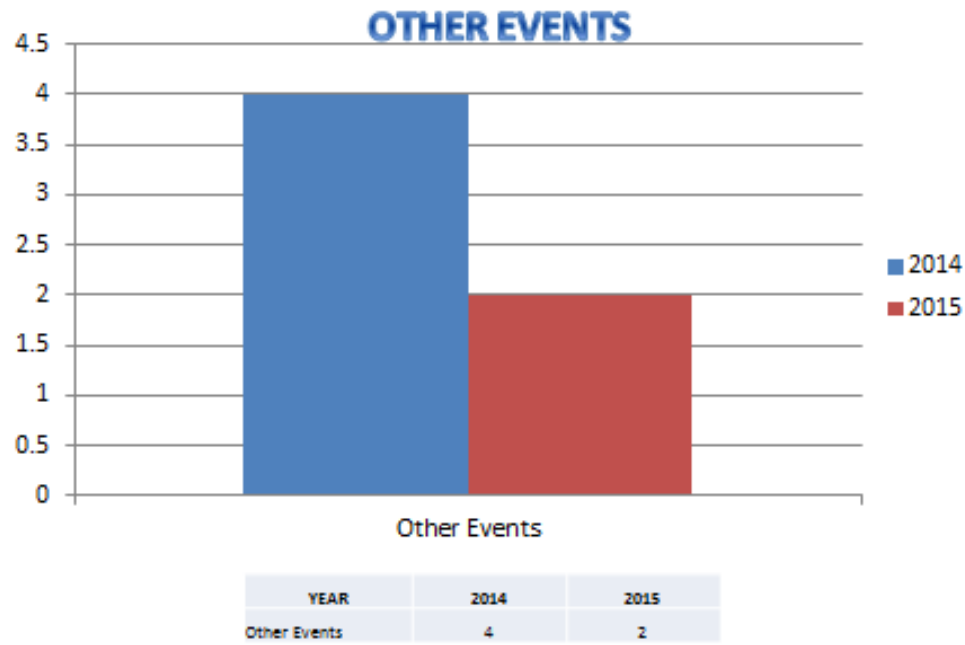

\section{Discussion}

For the whole year of 2014, 123 cases were reported consisting of 112 cases reported by nurses and the balance of 11 cases were reported by staff from other services such as pharmacy, medical record, laboratory, diagnostic imaging, finance and human resource.

\section{Patient Fall}

Based on the data collected for year 2014 and 2015, it was found that the number of cases of patient falls in 2014 was 16 and in 2015 was 11 cases.For year 2014 the breakdown of patient falls are as follows: fall from height, 1 case. found on the floor, 5 cases and trip / slip same level,10cases. For 2015,the breakdown of patient falls are as follows: fall from height, 3 cases, found on the floor,4 cases and trip / slip same level,4 cases.Therefore there was a reduction of 5 cases in 2015 compared to 2014.Looking at the high number of patient falls, policy changes was made in July 2015 to reduce the number of cases. Based on the data collected from January to June 2015, total number of cases was 6 and from July to December 2015 reduce to 5 cases.Process changes that had been implemented effective July 2015 are as follows: to place the fall prevention policy at patient bedside, distribute the fall prevention pamphlet to all patients, reinforcement of practices, 
monthly audit, continuous training and conduct regular CME. In conclusion with the implementation of new policy, number of cases had reduced from $6\left(1^{\text {st }}\right.$ half of 2015) to $5\left(2^{\text {nd }}\right.$ half of 2015).

The most significant reduction is on the number patient found on the floor where there was no reported case for the $2^{\text {nd }}$ half of 2015 .

\section{Medication Error, Medication Related Event}

Based on the data collected it was found that the total number of medication related event for 2014 was 14 cases and 12 cases for 2015.For 2014 there was 1 case of near miss administration by Nursing. Ten cases of adverse event were reported due to administration by Nursing and 3 cases due to dispensing / preparation by Pharmacy staff.In 2015, no reported near miss of administration by Nursing, 11 cases adverse event due to administration by Nursing and 1 case of wrong dispensing / preparation by Pharmacy staff.Due to high number of Nursing medication related events in 2015 and $1^{\text {st }}$ half of 2016 a policy changes was made to reduce the number of cases.The policy changes was implemented in July 2016 with the following details: competency consisting of nursing audit, yearly competency monitoring, bedside monitoring by doing audit and continuous training, knowledge consisting of CME Program, Pharmacist ward round and sharing RCA of incident, communication Skills consisting of encouraging prescribers to utilize E-Prescription and compulsory practice of SBAR during handing over reports. Before implementation of policy changes, for the $1^{\text {st }}$ half of 2015 administration error by Nursing was 11 cases. However after the implementation of policy changes the number had reduced significantly to only 1 case.In conclusion it was found that the policy changes were effective in reducing the medication related event.

\section{Sentinel event}

Based on the data collected for year 2014 and 2015 it was found that only 1 case of sentinel event reported in February 2015 where a patient was trying to commit suicide. This patient jumped from $2^{\text {nd }}$ floor to $1^{\text {st }}$ floor by climbing through the fence located at the $2^{\text {nd }}$ floor. However this patient survived with minor injury and was referred to General Hospital for further management of psychiatry problem.RCA was conducted and discussed during Risk Committee Meeting.It was recommended to raise the height of the fence on the $2^{\text {nd }}$ floor which later presented to Board of Directors for approval. The Board of Directors had given the approval and the job was completed in October 2015.

\section{Blood transfusion related event}

For year 2014 there was no reported case of Blood Transfusion Related Event. However in 2015 there were 2 cases consisting of 1 case with prolonged blood transfusion and 1 case of wrong blood result. However there were no process changes that had been implemented.

\section{Sharp injury}

2 reported cases of sharp injury in 2014 and 4 reported cases of sharp injury in 2015. The 2 cases in 2014 involved cleaning staff who pricked her finger while cleaning the sink and 1 Medical Officer who pricked his left palm while inserting cannula to patient.For year 2015, two cases involving 2 staff nurses, 1 phlebotomy and the other case involving Consultant who pricked his hand while inserting cannula to patient.

\section{OSH related matters}

Based on the data collected, there were 5 cases of OSH related event in 2014 and 2 cases reported in 2015.In January 2014, one staff fell down in ward with no injury and in June 2014, one staff injured her left thigh while transferring patient for emergency LSCS.In October 2014, two staff were involved in OSH related event where one staff knocked his head against the edge of high alert medication cabinet and for the other case a cleaning staff was being splashed by chemical on the right eye. One patient injured his mouth while doing angiogram procedure in November 2014.For 2015, there were only 2 reported cases where one staff injured her fight leg due two malfunction of dialysis chair. The other case happened in June 2015 where staff injured her leg while carrying bicarbonate solution.

\section{Nursing services, nursing related incident}

5 cases of Nursing Related Incident were reported in 2014 and 4 cases reported in 2015.For 2014, cases are as follows: wrong label of baby in April, wrong patient name in November and wrong signing of medication chart happened in December 2014.For 2015 only 2 reported cases consisting of wrong medication chart in January and wrong printing of patient's name in February 2015.Also reported under Nursing Related Incident was 1 case of thrombolysis in 2014 and 2 cases in 2015.

\section{Nursing services, ICU services}


In 2014, there was 1 reported case of ETT / monitoring line dislodge from patient undergoing intubation in ICU. However there was no reported case in 2015.

\section{Nursing services, OT services \&CSSS}

For 2014, one case of chemical spillage was reported in October 2014. Cleaning staff was splashed by chemical on his face when he was cleaning the sink.In October 2015 during Orthopaedic operation, tendon graft hold by Staff Nurse fell down on the floor and was not able to be used for that operation.

\section{Nursing services, departure from clinical best practice}

Seven cases of delayed by Surgeons >30 minutes due to Surgeon's absent were reported in 2014. However there was no reported case in 2015.There was 1 case of patient with GA >10 minutes before Surgeon arrival. This incident happened in 2014. However there was no reported case in 2015.Therefore total departure from clinical best practice reported for 2014 was 8 cases but no case reported in 2015 .

\section{Hospital wide / general event}

One case of burnt was reported in 2014 at Physiotherapy Services due to hot pack and another case reported in 2015 due to Teralaser machine. Three cases of unpredicted complication within 24 hours happened in 2014 where 2 patients died due to acute myocardial infection while doing procedure in Cathlab. One case was reported at Diagnostic Imaging Services where patient was having dorsal swollen after IV contrast procedure in 2014.For 2014, there were 2 unexpected deaths due to injection pethidine given to of end stage renal patient and another case septicaemic shock secondary to bowel perforation.

\section{Medical report}

In May 2015 there was a reported case of folder missing from the main storage area and police report was made accordingly.For 2015 no case was reported.

\section{Clinical support incident, lab service related incident}

In July 2014 there was 1 reported case of wrong result being issued by the Laboratory Services, 2 cases of service interruption due to ABG machine were reported in December 2014.The $1^{\text {st }}$ case was due to ABG machine taken by Paediatrician resulting in interruption to conduct the test and for the $2^{\text {nd }}$ case, Laboratory staff was not around causing failure to perform the test.For November 2015 there was 1 urine specimen of patient found missing.

\section{Diagnostic imaging service (dis) reporting, diagnosticimaging service (dis) related} incident

In September 2015 DIS staff came late to OT for C-Arm and in October 2015 x-ray film was wrongly label for 1 patient. For January 2015, x-ray was done on pregnant woman because patient was unaware that she is pregnant. Pregnancy was only confirmed after patient undergoing ultrasound scan.In December 2015 another case of pregnant woman undergoing $\mathrm{x}$-ray because patient was not aware that she is pregnant. She only came to know after the lab result was positive.

\section{Human capital}

In March 2015, one case of harassment of staff by patient. No case was reported in 2015.

\section{Equipment , device related incident}

There were 3 cases reported in 2014 and 3 cases reported in 2015. In March 2014 telescope was burnt by diathermy. In April 2015 sound system was not functioning at A\&E Services and in July 2015, DB at Dialysis Services burnt down.KCIS data were found missing in May 2015. In June 2015 bronchoscopy was not functioning at SPD Services and in October 2015 there was a reported case of suture needle broken at OT Services.

\section{Other event}

4 cases were reported in 2014 and 2 cases were reported in 2015. In July 20142 cases reported consisting of injury to patient on this face under the right eye due to scratching by ID band. Another case was reported where patient refused to give identity card to photocopy. 
In September 2015 there was 1 case of wrong registration of patient by staff followed by power supply failure in October 2015.Door knob was found broken by patient in April 2015 and in October 2015 patient was wrongly referred to Consultant.

For the whole year of 2014, there were 63 cases of clinical incidents reported but reduced to 48 cases in 2015. For non-clinical cases in 2014 there were 9 cases reported which increased to 11 cases in 2015.The most significant reduction of cases was related to OSH related events which reduced from 9 cases in 2014 to 2 cases in 2015. Departure from best clinical practice had recorded 10 cases in 2014 but no case was reported in 2015. Other incidents had not shown a very significant reduction in number of cases from 2014 to 2015.

Policy changes were implemented from the following cases:

i) Patient fall which had shown a reduction of cases from 16 in 2014 to 11 cases in 2015.

ii) Medication error where changes of policies were done for both pharmacy and nursing services. Cases had reduced from 14 cases in 2014 to 12 cases in 2015.

iii) Sentinel event in 2015, where the Management had raised the height of fence at the second floor.

Security related incident had increased from 3 cases in 2014 to 8 cases in 2015 where theft increased from 2 cases to 4 cases.

The Management had increased the installation of CCTV in many places to have a better surveillance in the critical areas.

2 cases of violence were reported in 2015. The first case is related to verbal abuse of staff nurse by patient and this was reported to the police. The second case is related to fighting between the security staff and both of them had been transferred out by the Security Company.

\section{Conclusion}

All incidents happening in 2014 and 2015 had been reported and tabulated accordingly. Data were analysed and trending for year 2014 was compared with year 2015. Looking at the high number of fall for 2014 and the first half of 2015 , policy changes was made in July 2015. As a result the number of fall had reduced from 16 cases in 2014 to only 11 cases in 2015 . For medication error related to administration by nursing, the number of cases was high in 2014 with 14 cases followed by 10 cases for the first half of 2015 . Therefore policy changes were implemented in July 2015 and as result the number of cases reduced to one only for the second half of 2015. Policy changes were also being implemented for sentinel event where the management had raised the height of the fence at second floor to prevent patient from jumping down. There was no change in policies for other types of incidents.Monitoring of incidents had enabled the Management of Hospital A to improve the quality of care and increase the safety provided to customers.

[1] Agency for Healthcare Research and Quality (AHRQ), 2010

References

[2] Agency for Healthcare Research and Quality (AHRQ), Users Guide: AHRQ Common Formats Version 1.1, March 2010, p. 1-2.

[3] AHRQ, Users Guide: AHRQ Common Formats Version 1.1, March 2010, p. 1-2.

[4] D.O. Farley, "Adverse-Event-Reporting Practices by US Hospitals: Results of a National Survey,” Quality and Safety in Health Care, 17, 2008, pp. 416-423

[5] J.C.Pham, Journal Public Health Research, What to do With Healthcare Incident Reporting System, 2013 Dec 1; 2 (3): e27.

[6] K.G. Shojania, "The Elephant of Patient Safety: What You See Depends on How You Look," The Joint Commission Journal on Quality and Patient Safety, 36, 2010, pp. 399-401.

[7] KPJ HealthacareBerhad, Guidelines on Root Cause Analysis, February 2007

[8] OIG, Adverse Events in Hospitals: Case Study of Incidence Among Medicare Beneficiaries in Two Counties, OEI-06-08-00220, December 2008

[9] P. Aspden, Patient Safety: Achieving a New Standard for Care, The National Academies Press, Washington, D.C., 2004.

[10] Pham JC, Kim GR, Natterman JP, et al. ReCASTing the RCA: an improved model for performing root cause analyses. Am J Med Qual 2010;25:186-91

[11] Stahel PF, Sabel AL, Victoroff MS, et al. Wrong-site and wrong-patient procedures in the universal protocol era: analysis of a prospective database of physician self-reported occurrences. Arch Surg 2010;145:978-84.

[12] T.K. Nuckols, "Rates and Types of Events Reported to Established Incident Reporting Systems in Two US Hospitals," Quality and Safety in Health Care, 16, 2007, pp. 164-168. 